\title{
Establishing the Substantive Interpretation of the GFP by Considering Evidence from Research on Personality Disorders and Animal Personality
}

\author{
Michael P. Hengartner ${ }^{1 *}$, Dimitri van der Linden ${ }^{2}$ and Curtis S. Dunkel ${ }^{3}$ \\ ${ }^{1}$ Department of Applied Psychology, Zurich University of Applied Sciences, Zurich, Switzerland, ${ }^{2}$ Department of Psychology, \\ Education, and Child Studies, Erasmus University Rotterdam, Rotterdam, Netherlands, ${ }^{3}$ Department of Psychology, Western \\ Illinois University, Macomb, IL, United States
}

Keywords: general factor of personality, social effectiveness, life history theory, animal personality, ethology, evolutionary biology, personality disorders, personality pathology

\section{OPEN ACCESS}

Edited by:

John F. Rauthmann,

Wake Forest University, United States

Reviewed by:

Konrad Senf,

University of Hohenheim, Germany

David Gallardo-Pujol,

University of Barcelona, Spain

*Correspondence:

Michael P. Hengartner

michaelpascal.hengartner@zhaw.ch

Specialty section:

This article was submitted to

Personality and Social Psychology,

a section of the journal

Frontiers in Psychology

Received: 17 May 2017

Accepted: 25 September 2017

Published: 09 October 2017

Citation:

Hengartner MP, van der Linden D and Dunkel CS (2017) Establishing the Substantive Interpretation of the GFP

by Considering Evidence from

Research on Personality Disorders and Animal Personality.

Front. Psychol. 8:1771

doi: 10.3389/fpsyg.2017.01771
In research on individual differences, various structural models aim at providing a comprehensive description of personality. These models assume multiple, mostly independent personality dimensions. More recently, the so-called General Factor of Personality (GFP) has become a proliferous, but contentious, topic. The notion of the GFP is based on the observations that personality dimensions are not independent, but in fact show consistent inter-correlations, leading to a relevant proportion of shared variance among them (Figueredo et al., 2006). The GFP seems to capture the socially desirable ends of personality scales, and, in terms of the Big Five model, high-GFP individuals score relatively high on openness, conscientiousness, extraversion (mainly the sociability-facet), agreeableness, and emotional stability (Rushton and Irwing, 2009; van der Linden et al., 2010a). Some authors have suggested that the GFP simply reflects methodological artifacts (Ashton et al., 2009; Backstrom et al., 2009; Hopwood et al., 2011b; Pettersson et al., 2012). However, much of this criticism has been addressed (Rushton and Erdle, 2010; Loehlin, 2012; Dunkel and van der Linden, 2014; van der Linden et al., 2014a). The objective of the present work is not to reiterate these issues, as they have been discussed extensively elsewhere (Irwing, 2013; van der Linden et al., 2016). Instead, we contend that criticism mostly offered within the specialty of personality psychology misses the bigger picture. More specific, evidence in favor of the GFP as a substantive and theoretically coherent construct has been provided in other research fields long before it became a contentious issue in personality psychology. Here we introduce two lines of evidence that may further corroborate the substantive interpretation of the GFP, specifically, findings from personality pathology as well as from animal personality. Looking at the GFP from a different perspective may help to overcome the current debates within personality psychology. In the following we will first briefly introduce work on the GFP and its theoretical foundation as social effectiveness. Afterwards we outline research from psychiatric nosology and animal ecology and discuss these in context.

\section{THE GFP REFLECTING SOCIAL EFFECTIVENESS}

Although most scholars would agree that a GFP can be identified in every assessment of personality dimensions, there is less consensus about the interpretation of this factor. Yet, one of its currently leading substantive interpretations is that the GFP largely reflects social effectiveness (Rushton et al., 2008; Loehlin, 2012; van der Linden et al., 2016). That is, high-GFP individuals seem to 
be characterized by a motivation to behave in socially desirable ways and by the tendency and ability to do so. As such, they would more often get along or get ahead socially which may enhance the probability of reaching their goals, such as, securing a desirable partner and easing access to socio-economic resources. A growing body of research supports this notion. First, measures of GFP have been found to overlap considerably with other constructs indicating social effective behavior (Dunkel and van der Linden, 2014). In a large meta-analysis, van der Linden et al. (2017) showed that the GFP has almost complete overlap ( $\rho=0.88)$ with trait emotional intelligence and moderate associations $(\rho=0.28)$ with ability emotional intelligence. A second line of evidence shows that the GFP relates to various criteria of social success, including peer-rated likeability and popularity and higher ratings on several objective socioeconomic performance indicators (van der Linden et al., 2010b, $2014 a, b)$. Those findings are in accordance with the view that the GFP does not merely reflect bias, but instead arise because high-GFP individuals genuinely tend to behave in a more socially desirable manner, while low GFP scores would be associated with problematic social behavior, including violence, delinquency, and impulsive sensation-seeking. However, as detailed below, such predispositions may be evolutionary adaptive in specific ecologies (Figueredo et al., 2006; Ellis et al., 2012). For instance, in deviant subcultures such as inmates, violent offenders score consistently lower on the GFP (van der Linden et al., 2015).

\section{EVIDENCE FROM PERSONALITY DISORDER RESEARCH}

Psychiatric research has made strong and compelling arguments for a general factor of personality pathology long before personality psychologists became aware of and started debating the GFP (see reviews by Bornstein, 1998; Tyrer, 2005). With respect to personality disorders $(\mathrm{PD})$, the general factor identified in those measures has received different terms, including severity of $\mathrm{PD}$, general personality dysfunction, or general personality pathology. Though these notions may differ in scope and content, they are largely overlapping and converge on the notion that the severity of (social) impairments related to PD is the defining feature. Hence, for the sake of simplicity we will hereinafter use the term General Factor of Personality pathology (GFPP). The GFPP has been extensively validated across two decades in phenotypic research on the structure of PD traits (Tyrer and Johnson, 1996; Deary et al., 1998; Seivewright et al., 2004; Hopwood et al., 2011a; Morey et al., 2011; Wright et al., 2012; Hengartner et al., 2014a; Kim et al., 2014; Bastiaansen et al., 2016). There is also evidence from behavioral genetic studies supporting the notion of the GFPP as a substantive and valid construct (Livesley et al., 1998; Kendler et al., 2008; ReichbornKjennerud, 2010). Consistent with the social effectiveness hypothesis of the GFP, it has been posited that the GFPP mainly captures social dysfunction and interpersonal problems (Hengartner et al., 2015; Tyrer et al., 2015). Indeed, a growing body of literature, including both cross-sectional epidemiologic community studies and prospective longitudinal clinical studies, has consistently demonstrated that the GFPP relates to social functioning deficits (Yang et al., 2010; Hopwood et al., 2011a; Hengartner et al., 2014b; Conway et al., 2016; Wright et al., 2016). Finally, recent advances in psychiatric nosology, based on both phenotypic and genetic research, now provide strong evidence for a general factor of psychopathology, coined the $p$ factor, at the apex of the hierarchical structure of psychopathology (Lahey et al., 2011, 2012; Laceulle et al., 2015; Pettersson et al., 2016). The $p$ factor extends the GFPP by accounting for covariance between all psychiatric syndromes, and not exclusively between PD traits. The $p$ factor shows meaningful associations with normative personality traits consistent with their GFP loadings, i.e., positive associations with neuroticism (or negative affectivity) and negative associations with agreeableness and conscientiousness (or effortful control; Tackett et al., 2013; Caspi et al., 2014; Castellanos-Ryan et al., 2016; Hankin et al., 2017). Nevertheless, to the best of our knowledge, a direct test of the association between the GFP, the GFPP and the $p$ factor has not been provided yet, though we note that the GFP has been related to a general health factor that contained general psychopathology (Figueredo et al., 2007; Figueredo and Rushton, 2009). A promising avenue for future research would hence be to directly test correlations between the GFP, the GFPP, and the $p$ factor. By putting these pieces together, researchers may further advance our understanding of the pervasive impact of personality on human health and social functioning (Ozer and Benet-Martinez, 2006; Smith and MacKenzie, 2006; Hengartner, 2015).

\section{EVIDENCE FROM ANIMAL PERSONALITY}

Research in ethology and evolutionary biology has shown that inter-individual variation in personality traits can be observed within and between animal taxa (Gosling, 2001; Reale et al., 2007). These studies confirm that personality is not unique to human, but rather a universal biological phenomenon with important implications for ecology and evolution (Wolf and Weissing, 2012). Because personality is moderately heritable in humans and other animals (Bouchard and Loehlin, 2001; Dochtermann et al., 2015), it was further proposed that personality trait variation must be subjected to natural selection (Nettle, 2006; Penke et al., 2007). In the following we will introduce an evolutionary model of animal personality based on life history (LH) theory (Roff, 2002), as LH theory plays also a crucial role in models of human GFP (Figueredo et al., 2006; Rushton et al., 2008). LH theory posits that individuals must allocate finite resources such as time and energy to competing $\mathrm{LH}$ traits including reproduction, health maintenance, mating, and parenting. Because resources are inherently limited, investment toward one trait reduces investments toward the others. As a result, trade-offs between $\mathrm{LH}$ traits emerge giving rise to a broad superordinate factor of LH strategy (LHS) that encompasses the extreme poles of fast vs. slow. Individuals following a fast LHS tend to invest relatively many resources into reproductive efforts. A slow LH strategy on the other hand, is characterized by higher investments toward somatic efforts (Roff, 2002; Jones, 2011). 
As detailed by two evolutionary models, selection for fast vs. slow LHS results in correlated personality traits due to tradeoffs between somatic and reproductive efforts (Stamps, 2007; Wolf et al., 2007). That is, individuals who invest heavily in early reproduction (fast LHS) must be bold and aggressive in order to outcompete rivals and attract mates, whereas individuals who delay reproduction (slow LHS) must be risk-averse, sociable, and docile, otherwise they would not survive long enough to benefit from future fitness returns (Hengartner, in press). Boldness-aggressiveness thus constitutes a behavioral syndrome, also termed proactive personality profile, whereas sociabilitydocility forms another syndrome, coined reactive personality profile (Groothuis and Carere, 2005; Koolhaas et al., 2010). Both syndromes are supposed to be extreme poles along a common GFP-like personality dimension that is co-adapted to LHS (Reale et al., 2010). That is, proactive personalities reflect low GFP scores (asocial, irritable, aggressive, and impulsive), while reactive personalities reflect high GFP scores (sociable, cautious, empathic, and self-controlled) (Hengartner, in press). Mounting evidence from different animal species now supports these personality profiles as correlates of LH traits (Biro and Stamps, 2008; Careau et al., 2009, 2010; Le Galliard et al., 2013; Niemela et al., 2013; Montiglio et al., 2014; Schuett et al., 2015; Binder et al., 2016; but see also Debecker et al., 2016). Noteworthy, Weiss et al. (2011) found no evidence for a GFP in the personality structure of chimpanzees, orang-utans, and rhesus macaques. However, their results were derived from a factor-analytic approach that neither included lower-order facets or primary items nor correlated trait-residuals. Research in humans has clearly shown that to successfully extract a GFP sometimes requires detailed structural modeling of lower-order facets and their interdependence (Rushton and Irwing, 2009). In correspondence, Latzman et al. (2014) extracted a hierarchical structure of personality in chimpanzees based on 43 primary items that was very similar to humans, including two higherorder factors corresponding to externalizing and internalizing personality. Since in humans externalizing and internalizing personality commonly load onto a GFP (Wright and Simms,

\section{REFERENCES}

Ashton, M. C., Lee, K., Goldberg, L. R., and de Vries, R. E. (2009). Higher order factors of personality: do they exist? Pers. Soc. Psychol. Rev. 13, 79-91. doi: $10.1177 / 1088868309338467$

Backstrom, M., Bjorklund, F., and Larsson, M. R. (2009). Five-factor inventories have a major general factor related to social desirability which can be reduced by framing items neutrally. J. Res. Pers. 43, 335-344. doi: 10.1016/j.jrp.2008. 12.013

Bastiaansen, L., Hopwood, C. J., Van Den Broeck, J., Rossi, G., Schotte, C., and de Fruyt, F. (2016). The twofold diagnosis of personality disorder: how do personality dysfunction and pathological traits increment each other at successive levels of the trait hierarchy? Personal. Disord. 7, 280-292. doi: $10.1037 /$ per0000149

Binder, T. R., Wilson, A. D. M., Wilson, S. M., Suski, C. D., Godin, J. G. J., and Cooke, S. J. (2016). Is there a pace-of-life syndrome linking boldness and metabolic capacity for locomotion in bluegill sunfish? Anim. Behav. 121, 175-183. doi: 10.1016/j.anbehav.2016. 09.006
2014; Hengartner et al., 2017), these findings raise the possibility of a GFP in chimpanzees, too.

\section{CONCLUSIONS AND OUTLOOK}

In the present paper we argued that the GFP likely represents a substantive factor that can contribute to integrate the literature from various fields on individual differences, including normative personality, personality pathology, LH theory, and animal personality. The literature briefly reviewed suggests that it would appear misguided to refute the GFP as a methodological artifact. Instead, we propose that future research in personality psychology should put more emphasis on the phylogenetic and ontogenetic origin of the GFP as a measure of social effectiveness that aligns with LHS. In humans, the GFP has been shown to correlate strongly with LHS (Figueredo et al., 2007; Figueredo and Rushton, 2009; Dunkel et al., 2012), but unfortunately all these human studies relied exclusively on subjective selfreport assessments of LHS (Figueredo et al., 2013). Linkage with animal personality as well as implementation of objective biological LH measures routinely applied in ethological research (e.g., age at first reproduction), would therefore considerably improve the validity of human GFP research. Moreover, linking the evolutionary origins of the GFP with psychiatric nosology may help to explain the pervasive socio-ecological impairments related to the GFPP (Hopwood et al., 2011a; Hengartner et al., 2014b; Wright et al., 2016). Finally, because it is supposed that both slow and fast LHS entail fitness benefits depending on contingent environmental demands (Ellis et al., 2009), it would be necessary to extend the social effectiveness hypothesis of the GFP by focusing on the adaptive solutions provided by both high and low GFP-scores (Figueredo et al., 2006; Sherman et al., 2013).

\section{AUTHOR CONTRIBUTIONS}

MH drafted the manuscript. DvdL and CD participated in writing and critical revision of the manuscript. All authors approved the final version.

Biro, P. A., and Stamps, J. A. (2008). Are animal personality traits linked to life-history productivity? Trends Ecol. Evol. 23, 361-368. doi: $10.1016 /$ j.tree.2008.04.003

Bornstein, R. F. (1998). Reconceptualizing personality disorder diagnosis in the DSM-V: the discriminant validity challenge. Clin. Psychol. Sci. Pract. 5, 333-343. doi: 10.1111/j.1468-2850.1998.tb00153.x

Bouchard, T. J. Jr. and Loehlin, J. C. (2001). Genes, evolution, and personality. Behav. Genet. 31, 243-273. doi: 10.1023/A:1012294324713

Careau, V., Bininda-Emonds, O. R. P., Thomas, D. W., Reale, D., and Humphries, M. M. (2009). Exploration strategies map along fast-slow metabolic and life-history continua in muroid rodents. Funct. Ecol. 23, 150-156. doi: 10.1111/j.1365-2435.2008.01468.x

Careau, V., Reale, D., Humphries, M. M., and Thomas, D. W. (2010). The pace of life under artificial selection: personality, energy expenditure, and longevity are correlated in domestic dogs. Am. Nat. 175, 753-758. doi: 10.1086/652435

Caspi, A., Houts, R. M., Belsky, D. W., Goldman-Mellor, S. J., Harrington, H., Israel, S., et al. (2014). The p factor: one general psychopathology factor in the structure of psychiatric disorders? Clin. Psychol. Sci. 2, 119-137. doi: $10.1177 / 2167702613497473$ 
Castellanos-Ryan, N., Briere, F. N., O’Leary-Barrett, M., Banaschewski, T., Bokde, A., Bromberg, U., et al. (2016). The structure of psychopathology in adolescence and its common personality and cognitive correlates. J. Abnorm. Psychol. 125, 1039-1052. doi: 10.1037/abn0000193

Conway, C. C., Hammen, C., and Brennan, P. A. (2016). Optimizing prediction of psychosocial and clinical outcomes with a transdiagnostic model of personality disorder. J. Pers. Disord. 30, 545-566. doi: 10.1521/pedi_2015_29_218

Deary, I. J., Peter, A., Austin, E., and Gibson, G. (1998). Personality traits and personality disorders. Br. J. Psychol. 89, 647-661. doi: 10.1111/j.2044-8295.1998.tb02708.x

Debecker, S., Sanmartin-Villar, I., de Guinea-Luengo, M., Cordero-Rivera, A., and Stoks, R. (2016). Integrating the pace-of-life syndrome across species, sexes and individuals: covariation of life history and personality under pesticide exposure. J. Anim. Ecol. 85, 726-738. doi: 10.1111/1365-2656.12499

Dochtermann, N. A., Schwab, T., and Sih, A. (2015). The contribution of additive genetic variation to personality variation: heritability of personality. Proc. $R$. Soc. B Biol. Sci. 282, 1798. doi: 10.1098/rspb.2014.2201

Dunkel, C. S., and van der Linden, D. (2014). Evidence for the general factor of personality as social-effectiveness. Pers. Indiv. Dif. 64, 147-151. doi: 10.1016/j.paid.2014.02.030

Dunkel, C. S., Kim, J. K., and Papini, D. R. (2012). The general factor of psychosocial development and its relation to the general factor of personality and life history strategy. Pers. Indiv. Dif. 52, 202-206. doi: $10.1016 /$ j.paid.2011.10.016

Ellis, B. J., Del Giudice, M., Dishion, T. J., Figueredo, A. J., Gray, P., Griskevicius, V., et al. (2012). The evolutionary basis of risky adolescent behavior: implications for science, policy, and practice. Dev. Psychol. 48, 598-623. doi: $10.1037 / \mathrm{a} 0026220$

Ellis, B. J., Figueredo, A. J., Brumbach, B. H., and Schlomer, G. L. (2009). Fundamental dimensions of environmental risk. The impact of harsh versus unpredictable environments on the evolution and development of life history strategies. Hum. Nat. 20, 204-268. doi: 10.1007/s12110-009-9063-7

Figueredo, A. J., and Rushton, J. P. (2009). Evidence for shared genetic dominance between the general factor of personality, mental and physical health, and life history traits. Twin Res. Hum. Genet. 12, 555-563. doi: 10.1375/twin.12.6.555

Figueredo, A. J., de Baca, T. C., and Woodley, M. A. (2013). The measurement of human life history strategy. Pers. Indiv. Dif. 55, 251-255. doi: 10.1016/j.paid.2012.04.033

Figueredo, A. J., Vasquez, G., Brumbach, B. H., and Schneider, S. M. (2007). The K-factor, covitality, and personality: a psychometric test of life history theory. Hum. Nat. 18, 47-73. doi: 10.1007/BF02820846

Figueredo, A. J., Vasquez, G., Brumbach, B. H., Schneider, S. M. R., Sefcek, J. A., Tal, I. R., et al. (2006). Consilience and life history theory: from genes to brain to reproductive strategy. Dev. Rev. 26, 243-275. doi: 10.1016/j.dr.2006.02.002

Gosling, S. D. (2001). From mice to men: what can we learn about personality from animal research? Psychol. Bull. 127, 45-86. doi: 10.1037/0033-2909.127.1.45

Groothuis, T. G., and Carere, C. (2005). Avian personalities: characterization and epigenesis. Neurosci. Biobehav. Rev. 29, 137-150. doi: 10.1016/j.neubiorev.2004. 06.010

Hankin, B. L., Davis, E. P., Snyder, H., Young, J. F., Glynn, L. M., and Sandman, C. A. (2017). Temperament factors and dimensional, latent bifactor models of child psychopathology: transdiagnostic and specific associations in two youth samples. Psychiatry Res. 252, 139-146. doi: 10.1016/j.psychres.2017.02.061

Hengartner, M. P. (2015). The detrimental impact of maladaptive personality on public mental health: a challenge for psychiatric practice. Front. Psychiatry 6:87. doi: 10.3389/fpsyt.2015.00087

Hengartner, M. P. (in press). The evolutionary life history model of externalising personality: bridging human and animal personality science to connect ultimate and proximate mechanisms underlying aggressive dominance, hostility, and impulsive sensation seeking. Rev. Gen. Psychol. doi: 10.1037/ gpr0000127

Hengartner, M. P., Ajdacic-Gross, V., Rodgers, S., Muller, M., and Rossler, W. (2014a). The joint structure of normal and pathological personality: further evidence for a dimensional model. Compr. Psychiatry 55, 667-674. doi: 10.1016/j.comppsych.2013.10.011

Hengartner, M. P., de Fruyt, F., Rodgers, S., Müller, M., Rossler, W., and Ajdacic-Gross, V. (2014b). An integrative examination of general personality dysfunction in a large community sample. Personal. Ment. Health 8, 276-289. doi: $10.1002 / \mathrm{pmh} .1263$

Hengartner, M. P., Graf, M., and Schreiber, M. (2017). Traits across the personality hierarchy differentially relate to positive and negative affect: evidence for the predictive validity of empirically derived meta-traits. Personal. Ment. Health 11, 132-143. doi: 10.1002/pmh.1366

Hengartner, M. P., von Wyl, A., Tanis, T., Halmi, W., Galynker, I., and Cohen, L. J. (2015). Severity of personality disorders and domains of general personality dysfunction related to attachment. Personal. Ment. Health 9, 195-207. doi: 10.1002/pmh.1297

Hopwood, C. J., Malone, J. C., Ansell, E. B., Sanislow, C. A., Grilo, C. M., McGlashan, T. H., et al. (2011a). Personality assessment in DSM-5: empirical support for rating severity, style, and traits. J. Pers. Disord. 25, 305-320. doi: $10.1521 /$ pedi.2011.25.3.305

Hopwood, C. J., Wright, A. G. C., and Donnellan, M. B. (2011b). Evaluating the evidence for the general factor of personality across multiple inventories. J. Res. Pers. 45, 468-478. doi: 10.1016/j.jrp.2011.06.002

Irwing, P. (2013). The general factor of personality: substance or artefact? Pers. Indiv. Dif. 55, 234-242. doi: 10.1016/j.paid.2013.03.002

Jones, J. H. (2011). Primates and the evolution of long, slow life histories. Curr. Biol. 21, R708-R717. doi: 10.1016/j.cub.2011.08.025

Kendler, K. S., Aggen, S. H., Czajkowski, N., Roysamb, E., Tambs, K., Torgersen, S., et al. (2008). The structure of genetic and environmental risk factors for DSMIV personality disorders: a multivariate twin study. Arch. Gen. Psychiatry 65, 1438-1446. doi: 10.1001/archpsyc.65.12.1438

Kim, Y. R., Blashfield, R., Tyrer, P., Hwang, S. T., and Lee, H. S. (2014). Field trial of a putative research algorithm for diagnosing ICD-11 personality disorders in psychiatric patients: 1 . Severity of personality disturbance. Personal. Ment. Health 8, 67-78. doi: 10.1002/pmh.1248

Koolhaas, J. M., de Boer, S. F., Coppens, C. M., and Buwalda, B. (2010). Neuroendocrinology of coping styles: towards understanding the biology of individual variation. Front. Neuroendocrinol. 31, 307-321. doi: 10.1016/j.yfrne.2010.04.001

Laceulle, O. M., Vollebergh, W. A. M., and Ormel, J. (2015). The structure of psychopathology in adolescence: replication of a general psychopathology factor in the trails study. Clin. Psychol. Sci. 3, 850-860. doi: $10.1177 / 2167702614560750$

Lahey, B. B., Applegate, B., Hakes, J. K., Zald, D. H., Hariri, A. R., and Rathouz, P. J. (2012). Is there a general factor of prevalent psychopathology during adulthood? J. Abnorm. Psychol. 121, 971-977. doi: 10.1037/a0028355

Lahey, B. B., van Hulle, C. A., Singh, A. L., Waldman, I. D., and Rathouz, P. J. (2011). Higher-order genetic and environmental structure of prevalent forms of child and adolescent psychopathology. Arch. Gen. Psychiatry 68, 181-189. doi: 10.1001/archgenpsychiatry.2010.192

Latzman, R. D., Kopkins, W. D., Keebaugh, A. C., and Young, L. J. (2014). Personality in chimpanzees (Pan troglodytes): exploring the hierarchical structure and associations with the vasopressin V1A receptor gene. PLoS ONE 9:e95741. doi: 10.1371/journal.pone.0095741

Le Galliard, J. F., Paquet, M., Cisel, M., and Montes-Poloni, L. (2013). Personality and the pace-of-life syndrome: variation and selection on exploration, metabolism and locomotor performances. Funct. Ecol. 27, 136-144. doi: 10.1111/1365-2435.12017

Livesley, W. J., Jang, K. L., and Vernon, P. A. (1998). Phenotypic and genetic structure of traits delineating personality disorder. Arch. Gen. Psychiatry 55, 941-948. doi: 10.1001/archpsyc.55.10.941

Loehlin, J. C. (2012). How general across inventories is a general factor of personality? J. Res. Pers. 46, 258-263. doi: 10.1016/j.jrp.2012.02.003

Montiglio, P. O., Garant, D., Bergeron, P., Messier, G. D., and Reale, D. (2014). Pulsed resources and the coupling between life-history strategies and exploration patterns in eastern chipmunks (Tamias striatus). J. Anim. Ecol. 83, 720-728. doi: 10.1111/1365-2656.12174

Morey, L. C., Berghuis, H., Bender, D. S., Verheul, R., Krueger, R. F., and Skodol, A. E. (2011). Toward a model for assessing level of personality functioning in DSM-5, part II: empirical articulation of a core dimension of personality pathology. J. Pers. Assess. 93, 347-353. doi: 10.1080/00223891.2011.577853

Nettle, D. (2006). The evolution of personality variation in humans and other animals. Am. Psychol. 61, 622-631. doi: 10.1037/0003-066X.61.6.622 
Niemela, P. T., Dingemanse, N. J., Alioravainen, N., Vainikka, A., and Kortet, R. (2013). Personality pace-of-life hypothesis: testing genetic associations among personality and life history. Behav. Ecol. 24, 935-941. doi: 10.1093/beheco/art014

Ozer, D. J., and Benet-Martinez, V. (2006). Personality and the prediction of consequential outcomes. Annu. Rev. Psychol. 57, 401-421. doi: 10.1146/annurev.psych.57.102904.190127

Penke, L., Denissen, J. J. A., and Miller, G. F. (2007). The evolutionary genetics of personality. Eur. J. Pers. 21, 549-587. doi: 10.1002/per.629

Pettersson, E., Larsson, H., and Lichtenstein, P. (2016). Common psychiatric disorders share the same genetic origin: a multivariate sibling study of the Swedish population. Mol. Psychiatry 21, 717-721. doi: 10.1038/mp.2015.116

Pettersson, E., Turkheimer, E., Horn, E. E., and Menatti, A. R. (2012). The general factor of personality and evaluation. Eur. J. Pers. 26, 292-302. doi: $10.1002 /$ per.839

Reale, D., Garant, D., Humphries, M. M., Bergeron, P., Careau, V., and Montiglio, P. O. (2010). Personality and the emergence of the pace-of-life syndrome concept at the population level. Philos. Trans. R. Soc. B 365, 4051-4063. doi: $10.1098 /$ rstb.2010.0208

Reale, D., Reader, S. M., Sol, D., McDougall, P. T., and Dingemanse, N. J. (2007). Integrating animal temperament within ecology and evolution. Biol. Rev. 82, 291-318. doi: 10.1111/j.1469-185X.2007.00010.x

Reichborn-Kjennerud, T. (2010). The genetic epidemiology of personality disorders. Dialogues Clin. Neurosci. 12, 103-114.

Roff, D. A. (2002). Life History Evolution. Sunderland, MA: Sinauer.

Rushton, J. P., and Erdle, S. (2010). No evidence that social desirability response set explains the general factor of personality and its affective correlates. Twin Res. Hum. Genet. 13, 131-134. doi: 10.1375/twin.13.2.131

Rushton, J. P., and Irwing, P. (2009). A general factor of personality in 16 sets of the big five, the Guilford-Zimmerman Temperament Survey, the California Psychological Inventory, and the Temperament and character inventory. Pers. Indiv. Dif. 47, 558-564. doi: 10.1016/j.paid.2009.05.009

Rushton, J. P., Bons, T. A., and Hur, Y. M. (2008). The genetics and evolution of the general factor of personality. J. Res. Pers. 42, 1173-1185. doi: 10.1016/j.jrp.2008.03.002

Schuett, W., Dall, S. R. X., Kloesener, M. H., Baeumer, J., Beinlich, F., and Eggers, T. (2015). Life-history trade-offs mediate 'personality' variation in two colour morphs of the pea aphid, Acyrthosiphon pisum. J. Anim. Ecol. 84, 90-101. doi: 10.1111/1365-2656.12263

Seivewright, H., Tyrer, P., and Johnson, T. (2004). Persistent social dysfunction in anxious and depressed patients with personality disorder. Acta Psychiatr. Scand. 109, 104-109. doi: 10.1046/j.1600-0447.2003.00241.x

Sherman, R. A., Figueredo, A. J., and Funder, D. C. (2013). The behavioral correlates of overall and distinctive life history strategy. J. Pers. Soc. Psychol. 105, 873-888. doi: 10.1037/a0033772

Smith, T. W., and MacKenzie, J. (2006). Personality and risk of physical illness. Annu. Rev. Clin. Psychol. 2, 435-467. doi: 10.1146/annurev.clinpsy.2.022305. 095257

Stamps, J. A. (2007). Growth-mortality tradeoffs and 'personality traits' in animals. Ecol. Lett. 10, 355-363. doi: 10.1111/j.1461-0248.2007.01034.x

Tackett, J. L., Lahey, B. B., van Hulle, C., Waldman, I., Krueger, R. F., and Rathouz, P. J. (2013). Common genetic influences on negative emotionality and a general psychopathology factor in childhood and adolescence. J. Abnorm. Psychol. 122, 1142-1153. doi: $10.1037 / \mathrm{a} 0034151$

Tyrer, P. (2005). The problem of severity in the classification of personality disorder. J. Pers. Disord. 19, 309-314. doi: 10.1521/pedi.2005.19.3.309

Tyrer, P., and Johnson, T. (1996). Establishing the severity of personality disorder. Am. J. Psychiatry 153, 1593-1597. doi: 10.1176/ajp.153.12.1593

Tyrer, P., Reed, G. M., and Crawford, M. J. (2015). Classification, assessment, prevalence, and effect of personality disorder. Lancet 385, 717-726. doi: 10.1016/S0140-6736(14)61995-4 van der Linden, D., Dunkel, C. S., and Petrides, K. V. (2016). The General Factor of Personality (GFP) as social effectiveness: review of the literature. Pers. Indiv. Dif. 101, 98-105. doi: 10.1016/j.paid.2016.05.020

van der Linden, D., Dunkel, C. S., Beaver, K. M., and Louwen, M. (2015). The unusual suspect: the General Factor of Personality (GFP), life history theory, and delinquent behavior. Evol. Behav. Sci. 9, 145-160. doi: 10.1037/ebs00 00027

van der Linden, D., Nijenhuis, J. T., and Bakker, A. B. (2010a). The general factor of personality: a meta-analysis of big five intercorrelations and a criterion-related validity study. J. Res. Pers. 44, 315-327. doi: 10.1016/j.jrp.2010.03.003

van der Linden, D., Oostrom, J. K., Born, M. P., van der Molen, H. T., and Serlie, A. W. (2014a). Knowing what to do in social situations. The general factor of personality and performance on situational judgment tests. J. Pers. Psychol. 13, 107-115. doi: 10.1027/1866-5888/a000113

van der Linden, D., Pekaar, K. A., Bakker, A. B., Schermer, J. A., Vernon, P. A., Dunkel, C. S., et al. (2017). Overlap between the general factor of personality and emotional intelligence: a meta-analysis. Psychol. Bull. 143, 36-52. doi: 10.1037/bul0000078

van der Linden, D., Scholte, R. H. J., Cillessen, A. H. N., Nijenhuis, J. T., and Segers, E. (2010b). Classroom ratings of likeability and popularity are related to the big five and the general factor of personality. J. Res. Pers. 44, 669-672. doi: 10.1016/j.jrp.2010.08.007

van der Linden, D., te Nijenhuis, J., Cremers, M., van de Ven, C., and van der Heijden-Lek, K. (2014b). The General Factor of Personality (GFP) relates to other ratings of character and integrity: two validity studies in personnel selection and training of the Dutch armed forces. Int. J. Select. Assess. 22, 261-271. doi: 10.1111/ijsa. 12075

Weiss, A., Adams, M. J., and Johnson, W. (2011). The big none: no evidence for a general factor of personality in chimpanzees, orangutans, or rhesus macaques. J. Res. Pers. 45, 393-397. doi: 10.1016/j.jrp.2011.04.006

Wolf, M., and Weissing, F. J. (2012). Animal personalities: consequences for ecology and evolution. Trends Ecol. Evol. 27, 452-461. doi: 10.1016/j.tree.2012.05.001

Wolf, M., van Doorn, G. S., Leimar, O., and Weissing, F. J. (2007). Life-history trade-offs favour the evolution of animal personalities. Nature 447, 581-584. doi: 10.1038 /nature05835

Wright, A. G., and Simms, L. J. (2014). On the structure of personality disorder traits: conjoint analyses of the CAT-PD, PID-5, and NEO-PI-3 trait models. Personal. Disord. 5, 43-54. doi: 10.1037/per0000037

Wright, A. G., Hopwood, C. J., Skodol, A. E., and Morey, L. C. (2016). Longitudinal validation of general and specific structural features of personality pathology. J. Abnorm. Psychol. 125, 1120-1134. doi: 10.1037/abn00 00165

Wright, A. G., Thomas, K. M., Hopwood, C. J., Markon, K. E., Pincus, A. L., and Krueger, R. F. (2012). The hierarchical structure of DSM-5 pathological personality traits. J. Abnorm. Psychol. 121, 951-957. doi: 10.1037/a00 27669

Yang, M., Coid, J., and Tyrer, P. (2010). Personality pathology recorded by severity: national survey. Br. J. Psychiatry 197, 193-199. doi: 10.1192/bjp.bp.110.0 78956

Conflict of Interest Statement: The authors declare that the research was conducted in the absence of any commercial or financial relationships that could be construed as a potential conflict of interest.

Copyright (c) 2017 Hengartner, van der Linden and Dunkel. This is an open-access article distributed under the terms of the Creative Commons Attribution License (CC $B Y)$. The use, distribution or reproduction in other forums is permitted, provided the original author(s) or licensor are credited and that the original publication in this journal is cited, in accordance with accepted academic practice. No use, distribution or reproduction is permitted which does not comply with these terms. 